Research article

\title{
Evaluation of the readability of online texts related with autism spectrum disorder
}

\author{
Aziz Kara \\ Department of Child and Adolescent Mental Health, Konya Training and Research Hospital, University of Health \\ Sciences, Konya, Turkey
}

\section{ABSTRACT}

Aim: There has been a rapid incline in the number of patients diagnosed with autism spectrum disorder (ASD), recently. The present study aims to analyze the content and readability of online Turkish texts, on Turkish websites related to autism spectrum disorder.

Methods: In order to collect the necessary data of the present study, Google (http://www.google.com.tr), a commonly used internet search engine in our country, was used. Hence 300 websites from the first ten generated pages after writing the keywords autism, atypical autism, and autism spectrum disorder on the search engine were analyzed. Out of these 300 sites, sites containing only advertisement, videos, images and sites containing less than ten sentences, chat and forum sites, commercial sales sites and news sites that do not contain information about ASD were excluded. The mean number of syllables, the average number of words with four syllables and above, the average number of words and readability values were calculated according to Ateşman and Bezirci-Y1lmaz.

Results: The mean number of words in the analyzed texts was $14.42 \pm 0.48$, of words with four syllables and above was $4.52 \pm 0.17$, of syllables was $2.92 \pm 0.01$ and the readability value of the texts analyzed is according to Bezirci-Y1lmaz was $14.68 \pm 0,52$ and according to Ateşman it was $43.72 \pm 1.45$. The mean number of words among the study groups is $(p=0.538)$, the mean number of words with four and more syllables is $(\mathrm{p}=0.548)$ and the mean number of syllables is $(\mathrm{p}=0.652)$, Bezirci-Y1lmaz readability value is $(p=0.772)$, Ateşman readability value is $(p=0.626)$ displaying no statistically significant difference.

Conclusion: As a result of this study, it was found that the data presented on the internet about ASD was far beyond the health literacy level of our people.

Keywords: Autism spectrum disorder, readability, internet information.

Copyright (C) 2019 experimentalbiomedicalresearch.com

Corresponding Author: Dr. Aziz Kara,

Department of Child and Adolescent Mental Health,

Konya Training and Research Hospital, University of

Health Sciences, Konya, Turkey

E mail: aziz.kara@yahoo.com

ORCID ID: https://orcid.org/0000-0003-0925-5723
Received 2019-07-13,

Revisions 2019-07-27

Accepted 2019-08-05,

Publication Date 2019-10-01 


\section{Introduction}

In recent years, the number of patients diagnosed with autism spectrum disorder (ASD) has been increasing rapidly. According to the Centers for Disease Control and Prevention (CDC) data in the United States (USA), ASD was diagnosed in one out of 150 children between 2000 and 2002, and in one out of sixty-eight children in 2010, with an increase in the ASD incidence more than double during this period $[1,2]$. In 2014, one out of fifty-nine children was diagnosed with ASD. This indicates an increase of $15 \%$ [3].

According to the CDC report published in 2014 , although the age of initial diagnosis went two years back and is now two years of age, most children are still diagnosed after the fourth year. Early diagnosis is, like in other conditions, of utmost importance in ASD. Supporting the healthy development of patients through early intervention methods and techniques could be probably the best opportunity for the increase of communication and social interaction skills [3].

Moreover, the use of the internet is increasing rapidly day by day. Patients and their relatives search for information about their diseases, mostly on the World Wide Web. However, the information present on the internet may not always be reader-friendly. People may still not have satisfying and accurate information after reading the information on the WWW. One of the underlying reasons for this, in fact, is the question of how readable the texts on web pages are.

The increasing number of studies conducted recently aim to reveal the readability of health literature. The readability of a text may vary according to the genre, style and difficulty as well as the background of the reader. Some of the text-related factors include increased sentence length, syntactic complexity and word length, number of syllables per word, passive voice usage, specific terminology, and presence of difficult words [4].

The concept of readability, providing quantitative data about texts, provides information on whether the text is understood easily by readers at a certain level by analyzing some properties of syllables, words, and sentences in a language. Factors affecting readability are; average word length, word frequency, multi-syllable words, average sentence length, number of indefinite words and average number of syllables. The readability of the sentence decreases as the number of words increases. In the assessment of readability, readability formulas have been developed using criteria such as the length of words and sentences and the number of syllables [5-8].

The readability level of a text can be calculated using various formulas developed for a particular language. In the United States, for a text to be easily read and understood, it has to be prepared according to the 6th to 8th-grade levels [9]. According to the 2015 data of Turkish Standards Institute (TSI), the mean duration of education in our country is reported to be six and a half year [10].

There are many formulas developed for readability analysis. Two types of readability formulas have been developed by Ateşman [7] and Bezirci-Y1lmaz [8] that can be employed for the Turkish language.

The present study aims to analyze the level of readability and the content of ASD texts presented on Turkish sites of WWW.

\section{Methods}

The presented study was conducted based on the permission obtained from the Board of Specialization and Education in Medicine of Health Sciences University Konya Education 
and Research Hospital dated 13th of June 2019 and enumerated 26-12. The present study is descriptive. Therefore, the necessary data was obtained from Google (http://www.google.com.tr), a commonly used internet search engine in our country. In June 2019, 300 websites derived from the first ten pages determined by writing the key words autism, atypical autism and autism spectrum disorder were included for the initial analysis. Out of these 300 sites, sites that were advertising, had only video and images, containing less than ten sentences, chat and forum sites, commercial sales sites and news sites that do not contain information about the disease were excluded. However, different pages of the same sites written at different times (news sites) and presenting different contents were included. The articles on the pages of different websites forming the bulk of data for the present study were transferred to Microsoft Word 2016 program. Headings, author names, site URL, and links in the content of the articles were removed in order to not to influence readability outcomes. These articles were transferred to the software program and their readability values according to Ateşman and Bezirci-Yılmaz formulas were calculated [7, 8]. The content of the sites, derived by inserting the keywords, presenting no exclusion criteria, were classified according to site creators. Hospital and rehabilitation center sites were categorized as Group 1, Association and Ministry of Health sites as Group 2, national news sites as Group 3, and medical platform sites as Group 4.

\section{Bezirci-Yılmaz, Readability Formula}

Bezirci and Y1lmaz have examined in 2010 Turkish book texts of different types and levels according to their readability scores via software developed using a software library by analyzing English readability scales used in various fields and with different scalar quantities and evaluating their suitability and adaptability into Turkish. Moreover, by identifying some demographic features of Turkish, they have proposed a new readability score formula for Turkish. The results of the readability formula show that the academic grade levels in our country are as follows: 1-8 primary, 9-12 high school, 12-16 undergraduate, 16 and above academic education [8].

$\mathrm{YOD}=\sqrt{ } \mathrm{OKS} \times((\mathrm{H} 3 \times 0,84)+(\mathrm{H} 4 \times 1,5)+$ $(\mathrm{H} 5 \times 3,5)+(\mathrm{H} 6 \times 26,25))$

YOD: New readability value

OKS: Average number of words

H3: Average number of words with three syllables

H4: Average of four-syllable words

H5: Average of five-syllable words

H6: Average number of words with 6 or more syllables

\section{Ateşman Readability Score}

It is a formula developed by Ateşman, by adapting the Flesch Reading Ease Formula [11] into Turkish, in 1997 based on the length of words and sentences. According to the Ateşman formula, if the readability score of a text is between 90-100, it is considered as very easy, between 70-89 as easy, between 50-69 as of moderate difficulty, between 30-49 as difficult, and between 1-29 as very difficult [7].

Ateşman readability formula: 198,825 - 40,175 $\mathrm{x}$ (total syllables / total words) - 2,610 x (total words / total sentences)

\section{Statistical analysis}

Descriptive statistics of the categorical data in the present study were shown by using frequency and percentage values and statistics 
of numerical data were shown by using mean and standard deviation. In the study, the Kruskal-Wallis test was used for numerical data comparisons between independent groups, and Chi-Square test was used for categorical data comparisons. All statistical analyses were performed two-ways, and a threshold level of $5 \%$ was determined for statistical significance limit within a 95\% confidence interval. Statistical Package for the Social Sciences (SPSS) 21 (IBM Inc, USA) software program was used for the analysis of the obtained data in the present study.

\section{Results}

In total, 300 websites, for each keyword 100, were derived from search engine and analyzed. Two hundred thirty of these websites met the determined exclusion criteria and were hence excluded from the study. The remaining 70 websites were met the inclusion criteria and were thus analyzed.

There were 28 websites in the first group, 7 in the second group, 17 in the third group and 18 in the fourth group.

The average number of words in the analyzed texts was $14.42 \pm 0.48$, the average number of words with four syllables and more was $4.52 \pm$ 0.17 , the average number of syllables was 2.92 \pm 0.01 , and the readability value according to Bezirci-Y1lmaz was $14.68 \pm 0, \quad 52$, the readability value according to Ateşman was 43.72 \pm 1.45 . There was no significant difference between the groups by the mean number of words $(\mathrm{p}=0.538)$, the average number of words consisting of four syllables and more $(p=0.548)$, the average of all syllables $\quad(p=0.652), \quad$ Bezirci-Y1lmaz readability value $(p=0.772)$, and Ateşman readability value $(p=0.626)$ (Table 1$)$.

On examining web sites according to Ateşman criteria, the readability ranges of the web sites varied from "very difficult," 10 texts, "difficult," 40 texts, and of "medium difficulty," 20 texts. None of the texts presented on the websites ranged was between "easy" and "very easy." There was no statistically significant difference between the study groups in terms of readability, according to Ateşman ( $p=0.627)$ (Table 2).

When the contents of the study sites were examined, $68(97.1 \%)$ were about autism causes, $56(80.0 \%)$ covered the symptoms of autism, and 41 (58.6\%) about autism diagnosis. $58(82.9 \%)$ of the sites had general information about treatment, $57(81.4 \%)$ about special education, $45 \quad(64.3 \%)$ about psychotherapy, $35 \quad(50.0 \%)$ about pharmacotherapy, and $17(24.3 \%)$ about alternative therapy in autism. Only $56(80.0 \%)$ websites had up to date data in the present study.

\section{Discussion}

Like all over the world, the number of children diagnosed with ASD is increasing in our country too. Hence, raising awareness for the early diagnosis and treatment of affected children is of the utmost importance. Nowadays, most parents will conduct research on the World Wide Web about any condition they suspect in their children before they would consult physicians or experts. Likewise, many parents conduct research on the internet about any diagnoses made related to their children due to the lack of time during the examination made by the physician. Therefore, accurate and readable online information on ASD is required in order to identify children with ASD early and to obtain optimal results via early intervention and treatment.

Kollia B. et al. [4] reported that the readability level of the information presented on websites about ASD was much higher than the 
Table 1. Readability scores of the study groups.

\begin{tabular}{|c|c|c|c|c|c|c|}
\hline Parameter & $\begin{array}{l}\text { All Sites } \\
n=70\end{array}$ & $\begin{array}{l}\text { Group } 1 \\
\mathrm{n}=\mathbf{2 8}(\% 40)\end{array}$ & $\begin{array}{l}\text { Group } 2 \\
n=7(\% 10)\end{array}$ & $\begin{array}{l}\text { Group } 3 \\
n=17(\% 24)\end{array}$ & $\begin{array}{l}\text { Group } 4 \\
n=18(\% 26)\end{array}$ & $p$ \\
\hline $\begin{array}{l}\text { Mean number of } \\
\text { words }\end{array}$ & $\begin{array}{l}14,42 \pm 0,48 \\
(7,81-26,2)\end{array}$ & $13,81 \pm 0,70$ & $14,46 \pm 2,33$ & $15,04 \pm 1,00$ & $14,74 \pm 0,89$ & 0,538 \\
\hline $\begin{array}{l}\text { Average number of } \\
\text { words with four and } \\
\text { more syllables }\end{array}$ & $\begin{array}{l}4,52 \pm 0,17 \\
(2,29-9,21)\end{array}$ & $4,23 \pm 0,22$ & $4,75 \pm 0,89$ & $4,61 \pm 0,31$ & $4,80 \pm 0,35$ & 0,548 \\
\hline $\begin{array}{l}\text { Average number of } \\
\text { syllables }\end{array}$ & $\begin{array}{l}2,92 \pm 0,01 \\
(2,71-3,18)\end{array}$ & $2,91 \pm 0,01$ & $2,90 \pm 0,04$ & $2,91 \pm 0,02$ & $2,95 \pm 0,02$ & 0,652 \\
\hline $\begin{array}{l}\text { Bezirci-Yılmaz } \\
\text { readability score }\end{array}$ & $\begin{array}{l}14,68 \pm 0,52 \\
(7,61-26-84)\end{array}$ & $14,06 \pm 0,73$ & $14,94 \pm 2,59$ & $15,03 \pm 1,03$ & $15,23 \pm 1,02$ & 0,772 \\
\hline $\begin{array}{l}\text { Ateşman readability } \\
\text { score }\end{array}$ & $\begin{array}{l}43,72 \pm 1,45 \\
(11,34-26,8)\end{array}$ & $45,48 \pm 2,05$ & $44,48 \pm 7,26$ & $42,58 \pm 2,71$ & $41,752,94$ & 0,626 \\
\hline
\end{tabular}

The values were presented as (Min-Max) and Mean \pm Std.Err.

Table 2. Readability ranges according Ateşman.

\begin{tabular}{|l|c|c|c|c|l|}
\hline $\begin{array}{l}\text { Readability ranges } \\
\text { according Ateşman }\end{array}$ & Group 1 & Group 2 & Group 3 & Group 4 & $\boldsymbol{p}$ \\
\hline Very difficult $(\mathbf{n}=\mathbf{1 0})$ & 2 & 2 & 3 & 3 \\
\hline Difficult (n=40) & 19 & 2 & 10 & 9 & \\
\hline Moderate difficulty (n=20) & 7 & 3 & 4 & 6 & 0,627 \\
\hline Easy (n=0) & 0 & 0 & 0 & 0 & \\
\hline Very easy (n=0) & 0 & 0 & 0 & 0 \\
\hline
\end{tabular}

recommended readability level for the public. In the relevant review of literature, no research on the readability of Turkish websites on autism was determined. Relevant readability studies about Turkish web sites revealed the study made by Kozanhan B. et al. [12] on anesthesiology patient information texts and the study of Aksoy N. et al. [13] on breast cancer patient education texts both revealing poor internet readability of the data presented on Turkish websites. In the present study, the readability level of the websites prepared in
Turkish about ASD is very low and well below the readability level recommended for the Turkish People.

The average sentence length in Turkish is 9-10 words according to Ateşman and 10-11 words according to Bezirci -Yilmaz. According to both researchers, the mean number of syllables is reported as 2.6 syllables. In our study, the average number of words in the sentence is $14.42 \pm 0.48$, the average number of syllables is $2.92 \pm 0.01$ and both of these values are higher than those indicated by Ateşman and 
Bezirci-Y1lmaz. This shows that the readability of the texts in the study is low. However, no statistically significant difference between the readability scores of the groups enrolled in the present study was determined. These results show that the readability of the texts presented on internet websites should be increased. To this end, texts made of sentences with fewer words, a word made of fewer syllables, and preference of frequently used words instead of medical terminology would increase readability [14, 15].

Besides the readability of the texts presented on internet websites, their content is also essential. On examining the content of the texts included in the study, it determined that the majority of the data presented were up to date and included information about the causes, symptoms, diagnostic process and treatment of ASD.

As a result of this study, the data about ASD present on Turkish web sites is far beyond the health literacy level of our people. The texts presented about ASD could be revised and prepared according to the literacy level of our people. This would enable us to diagnose children with autism at earlier ages and to be of more benefit to the patients as well as their relatives.

\section{Acknowledgment}

We would like to thank Asim Egemen Yllmaz, and Burak Bezirci for the software developed and for their allowance to be used in the present study.

\section{Funding sources: None}

\section{References}

[1]Van Naarden Braun K, Pettygrove $S$, Daniels J, Miller L, Nicholas J, Baio J, et al. Evaluation of a methodology for a collaborative multiple source surveillance network for autism spectrum disordersAutism and Developmental Disabilities Monitoring Network, 14 sites, United States, 2002. Morbidity and mortality weekly report Surveillance summaries (Washington, DC : 2002). 2007; 56(1): 2940.

[2]Baio J. Developmental Disabilities Monitoring Network Surveillance Year 2010 Principal Investigators; Centers for Disease Control and Prevention (CDC). Prevalence of autism spectrum disorder among children aged 8 years-Autism and developmental disabilities monitoring network, 11 sites, United States, 2010. MMWR Surveill Summ. 2014; 63(2): 1-21.

[3]Baio J, Wiggins L, Christensen DL, Maenner MJ, Daniels J, Warren Z, et al. Prevalence of Autism Spectrum Disorder Among Children Aged 8 Years - Autism and Developmental Disabilities Monitoring Network, 11 Sites, United States, 2014. Morbidity and mortality weekly report Surveillance summaries (Washington, DC : 2002). 2018; 67(6): 1-23.

[4]Kollia B, Basch CH, Kamowski-Shakibai MT, Tsiamtsiouris J, Garcia P. Testing the Readability of Online Content on Autism Spectrum Disorders. Advances in Neurodevelopmental Disorders. 2019; 3(1): 85-90.

[5]Boztaş N, Özbilgin Ş, Öçmen E, Altuntaş G, Özkardeşler S, Hancı V, et al. Evaluating the readibility of informed consent forms available before anaesthesia: a comparative study. Turk J Anaesthesiol Reanim. 2014; 42(3): 140-44.

[6]Durusu Tanriöver M, Yildırım HH, Demiray Ready FN, Çakır B, Akalın HE. Sağlık Okuryazarlığı Araştırması. 1. Baskı. Ankara: Sağlık-Sen Yayınları; 2014. p.93. 
[7]Ateşman E. Measuring readability in Turkish. AU Tömer Language Journal. 1997; 58(2): 171-74.

[8]Bezirci B, Y1lmaz A. A software library for measurement of readability of texts and a new readability metric for Turkish. DEÜ FMD. 2010; 12(3): 49-62.

[9]Friedman DB, Hoffman-Goetz L. A systematic review of readability and comprehension instruments used for print and web-based cancer information. Health Educ Behav. 2006; 33(3): 352-73.

[10] Yesilyurt M, Karadeniz O, Gulel F, Caglar A, Uyar S. Mean and expected years of schooling for provinces in Turkey. PJESS. 2016; 3(1): 1-7.

[11]Flesch R. A new readability yardstick. J Appl Phycol. 1948;32(3):221-33.

[12] Kozanhan B, Tutar MS. Readability of patient education texts presented on the internet in the field of anesthesiology. Turkiye Klinikleri J Anest Reanim. 2017;15(2):63-70.

[13] Aksoy N, Kozanhan B, Eryilmaz MA, Tutar MS. Assessment of the readability of patient education materials regarding breast cancer on websites. Fam Pract and Palliat Care. 2019; 4(1): 25-30.

[14]Jackson RH, Davis TC, Bairnsfather LE, George RB, Crouch MA, Gault H. Patient reading ability: an overlooked problem in health care. South Med J. 1991; 84(10): 1172-75.

[15] Walsh TM, Volsko TA. Readability assessment of internet-based consumer health information. Respir Care. 2008; 53(10): 1310-15. 